\title{
A profile of patients on ASA or NSAIDs hospitalized with gastrointestinal perforations
}

\author{
JAMES D BAILEY, ROBERT J BAILEY MD, RICHARD N FEDORAK MD
}

JD BAILEY, RJ BAILEY, RN FEDORAK. A profile of patients on ASA or NSAIDs hospitalized with gastrointestinal perforations. Can J Gastroenterol 1995;9(7):387-392.

BACKGROUND: In a recent clinical trial gastrointestinal tract perforations in patients on nonsteroidal anti-inflammatory drugs (NSAIDs) were found to occur with a frequency of $0.15 \%$, and possibly to be reduced in patients concomitantly using the cytoprotective agent misoprostol.

OBJECTIVE: To characterize patients with gastrointestinal perforations admitted to the two major referral teaching hospitals in Edmonton, Alberta between January 1, 1989 and December 31, 1993.

METHODS: A computerized search program was used to select patient charts containing preselected International Classification of Diseases (ICD) 9-CM codes, and patients were organized into four study groups based upon drug use: those taking NSAIDs, those taking acetylsalicylic acid (ASA), those taking both NSAIDs and ASA, and those taking neither NSAIDs nor ASA.

RESULTS: The following significant characteristics were identified in the 428 patients admitted with perforations: only a minority (29\%) were taking either NSAIDs or ASA; NSAID users were likely to be female, while those using neither NSAID nor ASA were more likely to be male; females were older than males; patients taking NSAIDs, ASA or both were more often asymptomatic at presentation compared with those not using these drugs; and upper gastrointestinal tract perforations were more likely to occur in the duodenum than in the stomach, while lower gastrointestinal tract perforations were more likely to occur in the colon than in the small intestine.

CONCLUSIONS: This retrospective descriptive study outlines the profile of a patient presenting to a referral hospital with a gastrointestinal perforation. Furthermore, it suggests that NSAID and/or ASA use significantly alters this profile compared with that in patients using neither NSAIDs nor ASA. (Pour le résumé, voir page 388)

Key Words: Acetylsalicylic acid (ASA), Intestinal perforation, Misoprostol, Nonsteroidal anti-inflammatory drug (NSAID), Ulceration \section{Alberta}

Division of Gastroenterology, Department of Medicine, University of Alberta, Edmonton,

Correspondence: Dr Richard N Fedorak, Division of Gastroenterology, Department of Medicine, University of Alberta, Edmonton, Alberta T6G 2C2. Telephone 403-492-6941, fax 403-492-3744, e-mail richard.fedorak@ualberta.ca

Received for publication June 30, 1995. Accepted September 25, 1995
$\mathrm{D}$ URING THE ANALYSIS OF MISOprostol Ulcer Complications Outcomes Safety Assessment (MUCOSA) trial an important outcome was identified involving nonsteroidal antiinflammatory drugs (NSAIDs) and gastrointestinal perforations. In this clinical trial, 8849 patients receiving a variety of NSAIDs were randomized to receive either misoprostol or placebo as a cytoprotective agent. Seven of the 4443 placebo patients $(0.15 \%)$ developed a gastrointestinal perforation. In contrast, only one of the 4406 patients taking misoprostol developed a gastrointestinal perforation $(\mathrm{P}<0.02)$ (1). These data suggest that NSAID use may be an important factor in the development of gastrointestinal perforation and that misoprostol may prevent these NSAID-induced perforations.

This descriptive study characterizes patients with gastrointestinal perforations admitted to the two major referral teaching hospitals in Edmonton, Alberta between January 1, 1989 and December 31, 1993. Patients who developed perforations while taking NSAIDs were compared with those taking acetylsalicylic acid (ASA), those taking both NSAIDs and ASA, and those taking neither NSAIDs nor ASA.

\section{PATIENTS AND METHODS}

Patients admitted to the University of Alberta Hospital and the Royal Alexandra Hospital between January 1, 


\section{Profil des patients sous AAS ou AINS hospitalisés pour perforation gastro-intestinale}

DONNÉES DE DÉPART : Lors d'un récent essai clinique, on a pu découvrir que les perforations gastro-intestinales survenaient à une fréquence de 0,15\% chez les patients traités par anti-inflammatoires non stéroïdiens (AINS) et qu'elles pouvaient être atténuées chez les patients à qui l'agent cytoprotecteur misoprostol était administré concomitamment.

OBJECTIF : Identifier les caractéristiques des patients atteints de perforations gastro-intestinales admis dans deux grands centres hospitaliers universitaires d'Edmonton, en Alberta, entre le $1^{\text {er }}$ janvier 1989 et le 31 décembre 1993.

MÉTHODES : Un programme de recherche informatisé a été utilisé afin de sélectionner les dossiers des patients renfermant des codes 9-CM de la classification internationale des maladies, et les patients ont été répartis entre quatre groupes selon les médicaments qui leur avaient été administrés : ceux qui prenaient des AINS, ceux qui prenaient de l'AAS, ceux qui prenaient les deux et ceux qui ne prenaient ni l'un ni l'autre.

RÉSULTATS : Les caractéristiques significatives suivantes ont été identifiées chez les 428 patients admis pour perforations : seule une minorité d'entre eux (29\%) prenaient des AINS ou de l'AAS; les utilisateurs d'AINS étaient davantage des femmes, alors que ceux qui ne prenaient ni AINS ni AAS étaient davantage des hommes; les femmes étaient plus âgées que les hommes; les patients sous AINS, AAS ou les deux étaient plus souvent asymptomatiques lors de leur admission, en comparaison avec les sujets qui ne prenaient pas de tels médicaments; et les perforations des voies digestives hautes s'observaient plus souvent au duodénum qu'à l'estomac, alors que les perforations des voies digestives basses affectaient davantage le côlon que l'intestin grêle.

CONCLUSIONS : Cette étude rétrospective dresse le profil du patient qui consulte à l'hôpital pour perforation gastro-intestinale. De plus, elle révèle que l'emploi d'AINS ou d'AAS altère significativement ce profil, comparativement aux cas où ni l'un ni l'autre de ces médicaments ne sont employés.

1989 and December 31, 1993 for gastric, duodenal, intestinal and colonic perforations diagnosed by surgery and/or $\mathrm{x}$-ray were considered eligible for the study. These two tertiary referral hospitals serve a population of approximately 1.5 million. Over the interval of the study there were 297,571 admissions to the two hospitals. Using a computerized search program, these admissions were screened to identify records that indicated a primary diagnosis of gastric ulcer perforation (International Classification of Diseases [ICD] 9-CM codes 531.1 to 531.6 except .3 and .4), duodenal ulcer (532.1 to 532.6 except .3 and .4$)$, peptic ulcer site unspecified (533.1 to 533.6 except .3 and .4), gastrojejunal ulcer (534.1 to 534.6 except .3 and .4 ) and perforation of the colon and intestine (569.83). In the above ICD 9-CM coding . 1 signifies acute with perforation, .2 signifies acute with hemorrhage and perforation, .3 signifies acute without mention of hemorrhage or perforation, .4 signifies chronic or unspecified without hemorrhage or perforation, .5 signifies chronic or unspecified with perforation and .6 signifies chronic or unspecified with hemorrhage and perforation.

This computerized record review identified 503 patient charts with the above ICD 9-CM codes. Each of these charts was manually reviewed systematically by a single researcher to document specific patient characteristics (Table 1). Of the 503 patient charts, only $428(0.144 \%$ of the total hospital admissions over the five-year study interval) had documented evidence of a gastrointestinal perforation (Figure 1). The remainder of the patient charts (75) were improperly coded, or contained no surgical or $\mathrm{x}$-ray documentation of perforation.

To compare the proportions of two categories within a single study group, data were analyzed using a $z$ test with the Yates correction for continuity.
To compare the distributions of two or more study groups within two or more categories, $\chi^{2}$ analysis was carried out. $\mathrm{P}$ values were determined using SigmaStat statistical software (Jandel Scientific Software, California) and deemed significantly different when $\mathrm{P}<0.05$.

\section{RESULTS}

The 428 patients with documented perforations (Figure 1) were organized into four study groups based on their drug use: those taking NSAIDs, those taking ASA, those taking both NSAIDs and ASA, and those taking neither NSAIDs nor ASA (Figure 2).

NSAID and ASA use: A significant majority of the 428 patients admitted with gastrointestinal perforations were taking neither NSAIDs nor ASA (71\%; 305 of 428) compared with those taking NSAIDs, ASA or both $(29 \% ; 123$ of 428) $(\mathrm{P}=0.001)$.

While it appeared that more patients were taking NSAIDs (19\%; 81 of 428) than ASA (7\%; 31 of 428$)$ this did not reach statistical significance $(\mathrm{P}=0.203)$. Very few were taking both NSAIDs and ASA $(3 \% ; 11$ of 428$)$. The frequency of a specific NSAID used in the 93 patients taking NSAIDs before their perforations (82 patients taking only NSAIDs and 11 patients taking both NSAIDs and ASA) is shown in Table 2 and parallels that previously reported (2).

Sex demographics: The number of male patients $(53 \%$; 228 of 428$)$ was similar to the number of female patients (47\%; 200 of 428) in the total study sample $(\mathrm{P}=0.254)$ (Figure 3$)$. However, when the groups were examined individually there were two study groups with statistical differences between male:female ratios. The majority of the NSAID users were female (64\%; 52 of 81$)(\mathrm{P}=0.028)$, while the majority of neither NSAID nor ASA users were male $(58 \% ; 176$ of 305$)$ $(\mathrm{P}=0.008)$. The group using ASA alone $(P=0.409)$ and the group using both NSAIDs and ASA $(P=0.789)$ did not demonstrate differences in female: male ratios.

Age demographics: Figure 4 demonstrates that in the total study sample fe- 


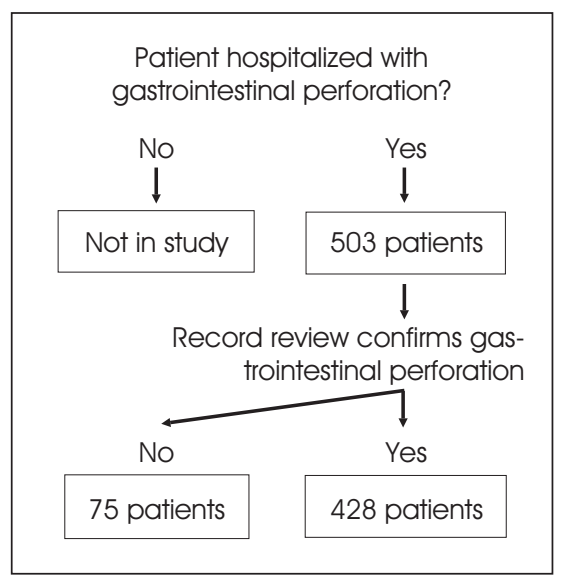

Figure 1) Study design. A total of 428 patients hospitalized between January 1989 and December 1993 matched the study criteria of International Classification of Diseases (ICD) 9-CM codes indicating gastrointestinal perforation

male patients were significantly older $(61 \pm 2$ years) at the time of perforation than their male counterparts $(56 \pm 2$ years) $(\mathrm{P}=0.008)$. However, within each study group age differences between females and males did not reach statistical significance (Figure 4). In contrast, when males were compared as a group, those using NSAIDs, ASA or both were older than those males taking neither drug $(\mathrm{P}=0.002)$. Similarly, when females were compared as a group, those using NSAIDs, ASA or both were older than those females taking neither drug $(\mathrm{P}=0.002)$.

Symptoms at presentation: In the total study sample there was no difference between the proportion of patients

TABLE 1

Information obtained from the chart review of patients admitted to the University of Alberta and the Royal Alexandra Hospitals with a gastrointestinal perforation between January 1, 1989 and December 31, 1993

\begin{tabular}{|c|c|}
\hline Information categories & Variables \\
\hline Demographics & $\begin{array}{l}\text { Sex } \\
\text { Age }\end{array}$ \\
\hline Drug use & $\begin{array}{l}\text { NSAID use } \\
\text { ASA use } \\
\text { Dose of medication } \\
\text { Duration of medication }\end{array}$ \\
\hline Clinical presentation & $\begin{array}{l}\text { Presence of symptoms } 48 \mathrm{~h} \text { before presentation } \\
\text { Admitted to hospital with perforation or developed } \\
\text { perforation in hospital }\end{array}$ \\
\hline $\begin{array}{l}\text { Diagnosis, therapy and } \\
\text { outcome }\end{array}$ & $\begin{array}{l}\text { Perforation location } \\
\text { Cause of perforation } \\
\text { Use of surgical therapy } \\
\text { Days in hospital } \\
\text { Days in intensive care unit } \\
\text { Number of units of blood transfused } \\
\text { Death as an outcome }\end{array}$ \\
\hline Co-morbid conditions & $\begin{array}{l}\text { Pulmonary conditions } \\
\text { Cardiac conditions } \\
\text { Gastrointestinal conditions } \\
\text { Rheumatoid or osteoarthritis }\end{array}$ \\
\hline Concomitant medication (type) & $\begin{array}{l}\text { Antacids } \\
\text { Anticholinergics } \\
\text { Sucralfate } \\
\mathrm{H}_{2} \text {-receptor antagonists } \\
\text { Misoprostol } \\
\text { Proton pump inhibitors } \\
\text { Prednisone }\end{array}$ \\
\hline History & $\begin{array}{l}\text { Past history of peptic ulcer disease } \\
\text { Family history of peptic ulcer disease }\end{array}$ \\
\hline
\end{tabular}

ASA Acetylsalicylic acid; NSAID Nonsteroidal anti-inflammatory drug

with symptoms at clinical presentation (54\%; 233 of 428$)$ and those asymptomatic at clinical presentation $(46 \%$; 195 of 428) $(\mathrm{P}=0.121)$. However, when each study group was examined individually, patients taking neither NSAID nor ASA were more likely to be sympto- matic $(57 \% ; 174$ of 305$)$ than asymptomatic $(43 \% ; 131$ of 305$)(\mathrm{P}=0.021)$. In contrast, patients in the other three groups were just as likely to be symptomatic as asymptomatic at presentation (patients taking NSAIDs: $47 \%$ symptomatic [38 of 81$]$ versus $53 \%$ asympto-

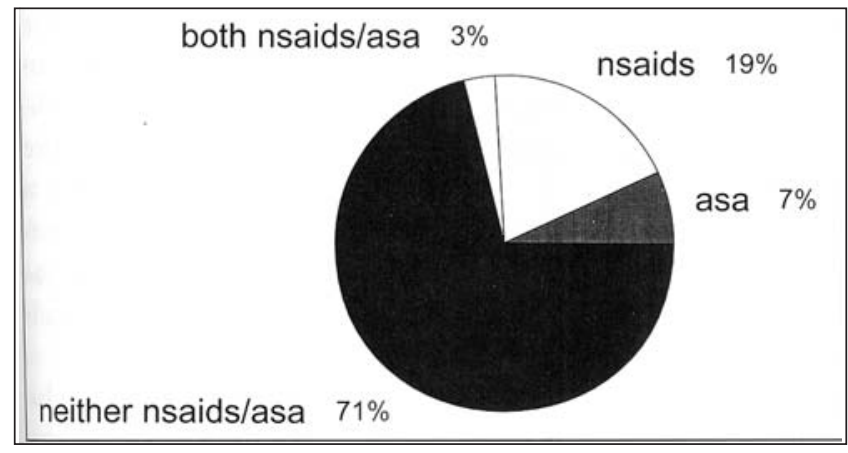

Figure 2) Percentage of patients in each study group ( total=428). Number of patients in each individual study group: nonsteroidal antiinflammatory drugs (NSAIDs), 81; acetylsalicylic acid (ASA), 31; both NSAIDs and ASA, 11; and neither NSAIDs nor ASA, 305. The majority of patients with perforations were taking neither NSAIDs nor ASA
TABLE 2

Specific NSAIDs used in the 93 patients taking NSAIDs before perforation

\begin{tabular}{lcc}
\hline NSAID & Number & Percentage \\
\hline Indomethacin & 29 & 30.9 \\
Diclofenac & 27 & 28.7 \\
Naproxen & 9 & 9.6 \\
Ketoprofen & 8 & 8.5 \\
Ketorolac & 5 & 5.3 \\
Sulindac & 4 & 4.3 \\
Piroxicam & 4 & 4.3 \\
Ibuprofen & 3 & 3.2 \\
Tolmetin & 1 & 1.1 \\
Not documented & 3 & 4.3 \\
Total & 93 & 100 \\
\hline
\end{tabular}

NSAIDs Nonsteroidal anti-inflammatory drugs 


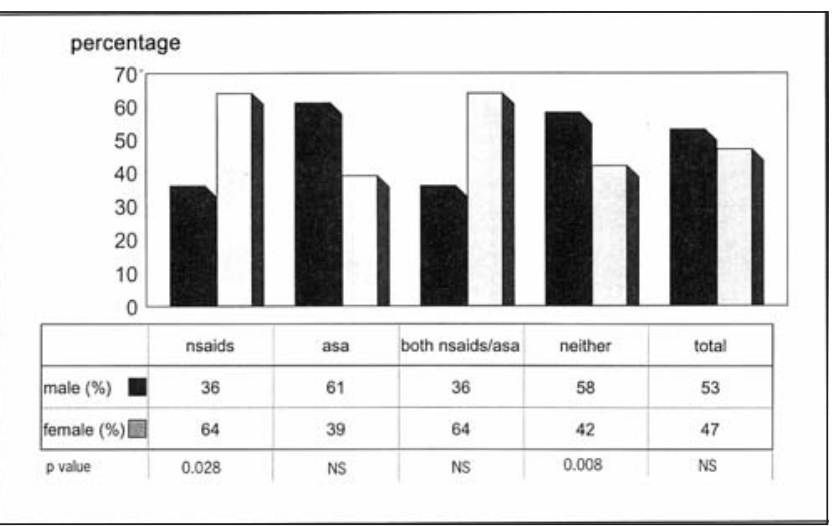

Figure 3) Percentage of females and males in each study group (total= 428: 200 females and 228 males). There were 81 nonsteroidal antiinflammatory drug (NSAID) patients ( 52 females, 29 males), 31 acetylsalicylic acid (ASA) patients (12 females, 19 males), 11 patients who took both NSAIDs and ASA (seven females, four males), and 305 patients who took neither NSAIDs nor ASA (129 females, 176 males). The majority of NSAID users were female, while the majority of patients using neither NSAID nor ASA were male. NS Not significant

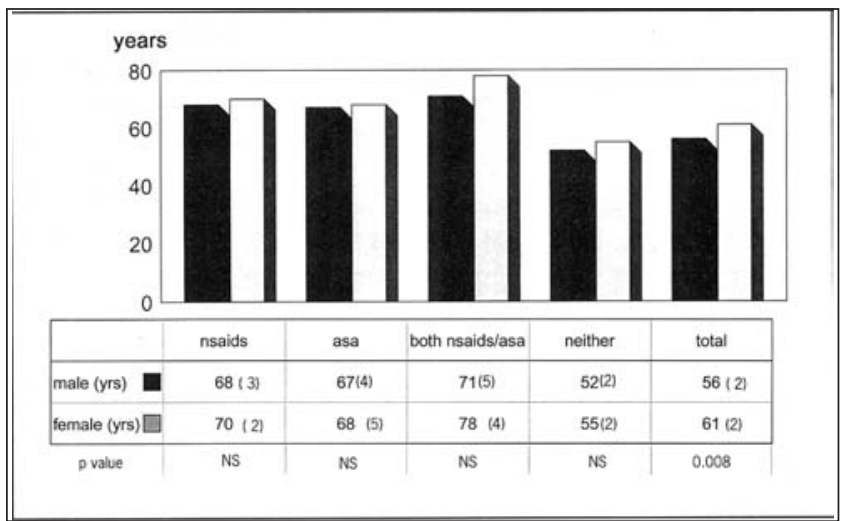

Figure 4) Age at presentation of perforation for females and males in each group. Values are expressed as mean (SEM). Females were significantly older at the time of perforation than males. In addition, females and males who used nonsteroidal anti-inflammatory drugs (NSAIDs), acetylsalicylic acid (ASA) or both tended to be older than those who took neither drug. NS Not significant

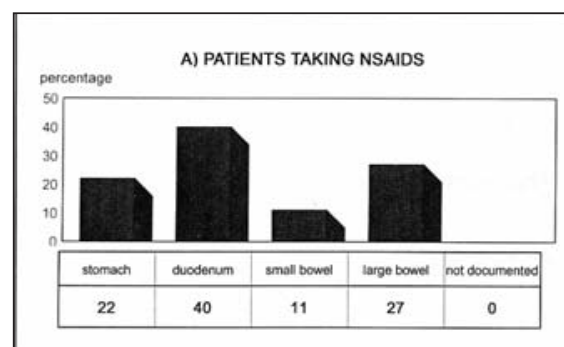

C) PATIENTS TAKING BOTH NSAIDS/ASA
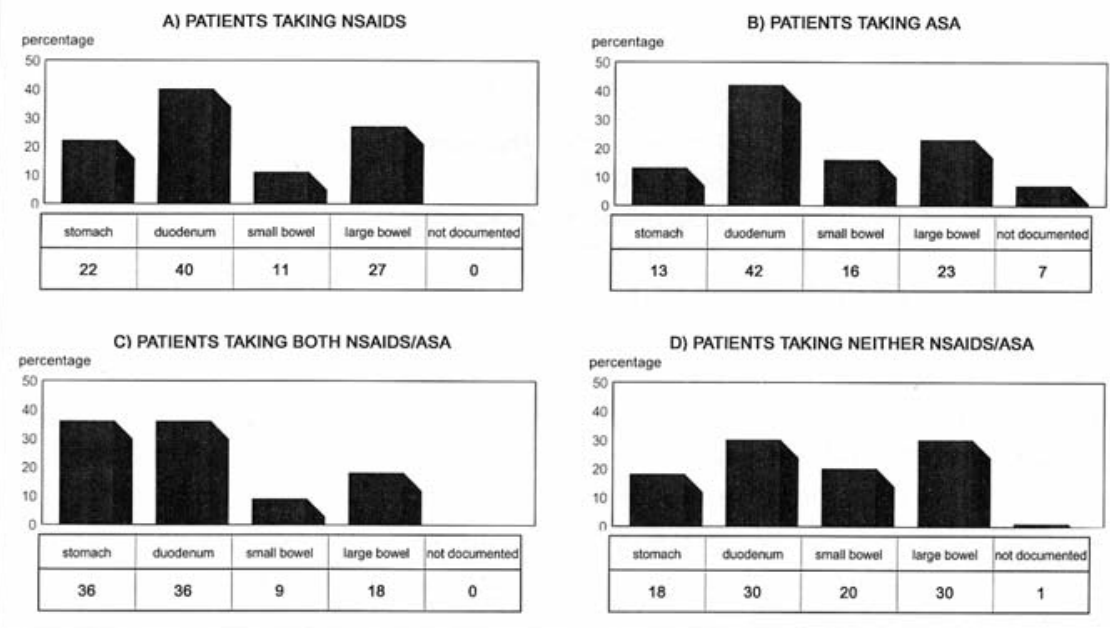

D) PATIENTS TAKING NEITHER NSAIDS/ASA

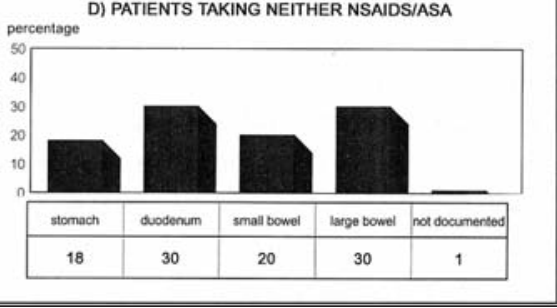

Figure 5) Location of perforation by individual study group. Total number of patients is 428 while the total number of perforations is 433 . Numbers in boxes refer to percentages. Of the 81 patients who took nonsteroidal anti-inflammatory drugs (NSAIDs), 18 had stomach perforations, 32 duodenal perforations, nine small bowel perforations and 22 large bowel perforations. Of the 31 patients who took acetylsalicylic acid (ASA), four had stomach perforations, 13 duodenal perfora- tions, five small bowel perforations, seven large bowel perforations and two undocumented locations. Of the 11 patients who took both NSAIDs/ASA, four had stomach perforations, four duodenal perforations, one small bowel perforation and two large bowel perforations. Of the 305 patients who took neither NSAIDs nor ASA, there were 310 total perforations: 57 stomach perforations, 94 duodenal perforations, 62 small bowel perforations, 93 large bowel perforations and four undocumented location. Upper gastrointestinal tract perforations were more likely to occur in the duodenum than the stomach while lower gastrointestinal tract perforations were more likely to occur in the colon than the small intestine

matic [43 of 81], $\mathrm{P}=0.752$; patients taking ASA: $55 \%$ symptomatic [17 of 31] versus $45 \%$ asymptomatic [14 of 31], $\mathrm{P}=0.847$; patients taking both drugs: $36 \%$ symptomatic [four of 11 ] versus $64 \%$ asymptomatic [seven of 11 ], $\mathrm{P}=0.855$ ).

Concomitant use of anti-ulcer medication before presentation: Of the 124 patients taking NSAIDs, ASA or both,
$15 \%$ (18) were on $\mathrm{H}_{2}$-receptor antagonists while only $7 \%$ (eight) were using misoprostol before presentation with a perforation. There was no difference in the concomitant anti-ulcer medication use within each study group.

Location of perforation: A total of 433 perforations were identified (five of the 428 patients had a perforation at more than one site). In the total study sample upper gastrointestinal tract perforations were more likely to occur in the duodenum $(33 \% ; 143$ of 433$)$ than in the stomach $(19 \% ; 83$ of 433$)$ $(\mathrm{P}=0.035)$. Similarly, in the total study sample lower gastrointestinal tract perforations were more likely to occur in the colon $(29 \% ; 124$ of 433$)$ than the small intestine (18\%; 77 of 433) $(\mathrm{P}=0.049)$. The locations of the remaining $1 \%$ of the perforations (six of 433) were not documented. Perforation location by individual study group is presented in Figure 5. While there was a trend towards a greater proportion of duodenal perforations in patients taking NSAIDs and patients taking ASA, this did not reach statistical significance.

Causes of perforation in patients taking neither NSAIDs nor ASA: Perforations in patients taking neither NSAID nor ASA were attributed to various causes including peptic ulcer disease $(46 \%)$, cancer $(14 \%)$, inflammatory bowel disease $(8 \%)$, infectious or 
TABLE 3

Causes of intestinal perforation in patients taking neither NSAIDs nor ASA

\begin{tabular}{lc}
\hline Cause & Number (\%) \\
\hline Peptic ulcer disease & $140(46)$ \\
Cancer & $44(14)$ \\
Inflammatory bowel & $25(8)$ \\
$\quad$ disease & $24(8)$ \\
Infectious/ischemic colitis & $19(6)$ \\
Diverticular disease & $11(4)$ \\
Operative complications & $5(2)$ \\
Trauma & $37(12)$ \\
Other/not documented &
\end{tabular}

ASA Acetylsalicylic acid; NSAIDs Nonsteroidal antiinflammatory drugs

ischemic colitis (8\%), diverticular disease $(6 \%)$, operative complications (4\%) and trauma (2\%) (Table 3). In $12 \%$ of cases the cause of the non-NSAID/ASA perforation was not documented.

Diagnosis and therapy: As shown in Table 4 surgical therapy was required in the vast majority of patients with perforations, regardless of study group. In addition, the use of NSAIDs, ASA or both before intestinal perforation did not significantly alter the duration of hospitalization or the interval spent in the intensive care unit.

Mortality rate: In the total study sample, $19 \%$ of patients (81 of 428) presenting with an intestinal perforation died. Figure 6 shows the mortality rates for each study group. There was no statistical difference in the proportion of deaths between study groups. Of interest, the more distal the perforation, the higher the mortality rate. Seven of 22 patients with colonic perforations (32\%) died, two of nine with small intestinal perforations (22\%) died, three of 18 with stomach perforations $(17 \%)$ died and two of 32 with duodenal perforation $(6 \%)$ died.

Unavailable information: Due to insufficient historical documentation a number of variables outlined in the initial study design (Table 1) were unobtainable. In particular, the dose and duration of ASA and NSAID use, comorbid conditions, and family and past history of peptic ulcer disease were poorly documented.

TABLE 4

Diagnosis and therapy

\begin{tabular}{|c|c|c|c|c|}
\hline & NSAIDs & ASA & $\begin{array}{c}\text { Both NSAIDs and } \\
\text { ASA }\end{array}$ & $\begin{array}{c}\text { Neither NSAIDs } \\
\text { nor ASA }\end{array}$ \\
\hline $\begin{array}{l}\text { Surgical therapy } \\
\text { number/total }\end{array}$ & 79/81 (98\%) & $27 / 31$ (87\%) & 10/1 1 (91\%) & $280 / 305$ (92\%) \\
\hline $\begin{array}{l}\text { Total days in } \\
\text { hospital }\end{array}$ & $\begin{array}{c}29.4 \pm 36.8 \\
\text { Range: } 0-206\end{array}$ & $\begin{array}{c}26.2 \pm 16.0 \\
\text { Range: } 0-84\end{array}$ & $\begin{array}{l}28.0 \pm 24.2 \\
\text { Range: } 7-87\end{array}$ & $\begin{array}{c}25.6 \pm 35.5 \\
\text { Range: } 0-258\end{array}$ \\
\hline Days in ICU & $\begin{array}{c}2.58 \pm 5.89 \\
\text { Range: } 0-158\end{array}$ & $\begin{array}{l}1.87 \pm 1.58 \\
\text { Range: } 0-6\end{array}$ & $\begin{array}{c}1.8 \pm 1.75 \\
\text { Range: } 0-5\end{array}$ & $\begin{array}{c}2.97 \pm 6.7 \\
\text { Range: } 0-258\end{array}$ \\
\hline
\end{tabular}

Values represent mean \pm SD. ASA Acetylsalicylic acid; ICU Intensive care unit; NSAIDs Nonsteroidal antiinflammatory drugs

\section{percentage}

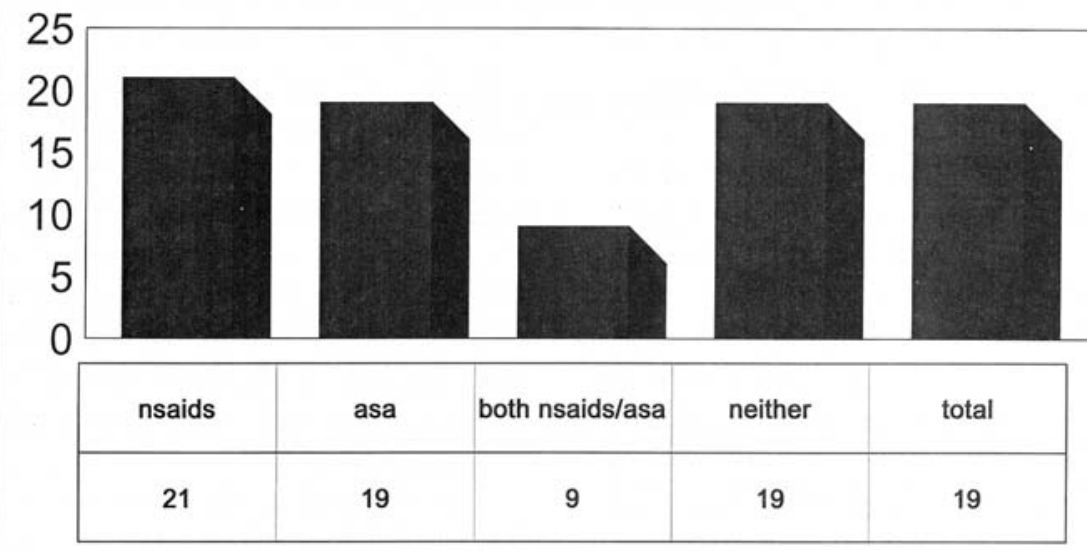

Figure 6) Mortality rates for each study group (total=428). Numbers in boxes refer to percentages. Number of deaths in each study group: nonsteroidal anti-inflammatory drugs (NSAIDs), 17 of 81; acetylsalicylic acid (ASA), six of 31 ; both NSAIDs and ASA, one of 11; neither NSAIDs nor ASA, 57 of 305

\section{DISCUSSION}

This descriptive study revealed that over a five-year interval 428 patients, representing $0.14 \%$ of the total number of admissions, presented with gastrointestinal perforations to the University of Alberta and Royal Alexandra Hospitals in Edmonton, Alberta. This perforation rate in patients using NSAIDs, ASA or both is identical to that previously identified (1). In the present study, 29\% of the total study group were taking NSAIDs, ASA or both (Figure 2). This high rate of association with NSAID and/or ASA use greatly exceeds the 7 to $10 \%$ rate of NSAID prescription in the Alberta population at any given time (Alberta Blue Cross Physician Prescribing Data Base). This high percentage of NSAID and/or ASA use among patients with gastrointestinal perforation implies more than a casual association.
The most frequently used NSAIDs in patients with perforation were indomethacin and diclofenac (Table 2), results that parallel those of a 1993 study at the University of Alberta Hospital (2). Furthermore, information from the Alberta Blue Cross Physician Prescribing Data Base indicates that the chance of a specific NSAID being associated with a patient presenting with perforations (Table 2) corresponds almost identically to the frequency with which that specific NSAID is prescribed. Thus, the association of a perforation with a specific NSAID likely relates to the frequency of its use rather than any specific NSAID-associated risk factor.

The fact that the majority of NSAID users were female (Figure 3 ) is likely attributable to the increased use of NSAIDs in the female population. Females are three times more likely than males to develop rheumatoid arthritis 
than males and to fill more NSAID prescriptions in all age groups (3). In contrast, men, being more likely to take ASA as effective therapy for primary and secondary prevention for myocardial infarction, made up the larger proportion of patients taking ASA (Figure 3).

In the total study group, females (61 \pm 2 years) were significantly older than males at the time of perforation ( $56 \pm 2$ years). Within male only and female only categories, those taking NSAIDs and/or ASA were older than those not taking any drug (Figure 4). The reason for these differences remains unclear but may reflect a number of factors including increased longevity of females, increased frequency of the female population in accessing health care and the increase in diseases requiring NSAID or ASA therapy in the elderly (4).

Considering both age and sex statistics, the group most associated with NSAID-related perforations was elderly

ACKNOWLEDGEMENTS: This study was supported by grants from the Alberta Heritage Foundation of Medical Research, the Medical Research Council of Canada and Searle Canada Inc.

\section{REFERENCES}

1. Silverstein FE, Geis GE, Struthers BJ and the MUCOSA study group. NSAIDs and gastrointestinal injury. Ann Intern Med 1995;123:241-9.

2. Rieder J, Saunders LD, Fedorak RN. A profile of patients on ASA or NSAIDs hospitalized with upper gastrointestinal bleeding. Can J Gastroenterol 1993;7:459-65.

3. Gabriel SE, Jaakkimainen L, Bombardier C. Risk for serious women. An effective prophylactic medication that prevents NSAID-related perforations in this high risk group would be beneficial $(3,5)$.

Patients who were taking neither drug before perforation were more likely to be symptomatic compared with patients who were on NSAIDs, ASA or both $(\mathrm{P}=0.021)$, which contrasts with the equal proportion of symptomatic and asymptomatic presentations in patients who develop gastrointestinal ulceration while on NSAIDs $(6,7)$. The reason for this discrepancy remains to be determined but may relate to the analgesic effects of the medications.

In the total study population, perforations that occurred in the upper gastrointestinal tract were more likely to involve the duodenum than the stomach $(\mathrm{P}=0.035)$, and perforations that occurred in the lower gastrointestinal tract were more likely to involve the colon than the small bowel $(\mathrm{P}=0.049)$

(Figure 5). In each study group this gastrointestinal complications related to use of nonsteroidal antiinflammatory drugs: A meta-analysis. Ann Intern Med 1991;115:787-96.

4. Guess HA, West R, Strand LM, et al. Fatal upper gastrointestinal hemorrhage or perforation among users and nonusers of nonsteroidal antiinflammatory drugs in Saskatchewan, Canada 1983. J Clin Epidemiol 1988;41:35-45.

5. Gabriel SE, Campion ME, O'Fallon WM. A cost-utility analysis of misoprostol prophylaxis for rheumatoid arthritis patients receiving nonsteroidal antiinflammatory drugs. Arthritis Rheum 1994;37:333-41.

6. Fries JF, Miller SR, Spitz PW, Williams CA, Hubert HB, Bloch DA. Toward trend towards more frequent perforations in the duodenum and colon persisted, but did not reach statistical significance. The higher incidence of perforations in the duodenum of the upper gastrointestinal tract parallels the site and frequency of NSAID- and non-NSAID-induced ulceration $(8,9)$. NSAID and/or ASA use did not increase the frequency of gastric or colonic perforations despite both drugs' predilection for causing gastric ulceration and for causing colonic mucosal injury in their sustained release formulations (9).

\section{CONCLUSIONS}

This retrospective descriptive study outlines group characteristics of patients presenting to a referral hospital with a gastrointestinal perforation. Furthermore, it suggests that the use of NSAIDs, ASA or both significantly alters this profile compared with that in patients using neither NSAIDs nor ASA.

an epidemiology of gastropathy associated with nonsteroidal anti-inflammatory drug use. Gastroenterology 1989;96:647-55.

7. Soll AH, Kurata J, McGulgan JE. Ulcers, nonsteroidal anti-inflammatory drugs, and related matters.

Gastroenterology 1989;96:561-8.

8. Redfern JS, Feldman M. Role of endogenous prostaglandins in preventing gastrointestinal ulceration: induction of ulcers by antibodies to prostaglandins. Gastroenterology 1989;96:596-605.

9. Gibson GR, Whitacre EB, Ricotti CA. Colitis induced by nonsteroidal antiinflammatory drugs: report of four cases and review of the literature. Arch Intern Med 1992;152:625-32. 


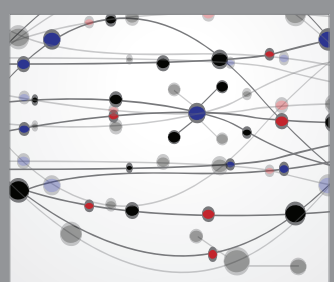

The Scientific World Journal
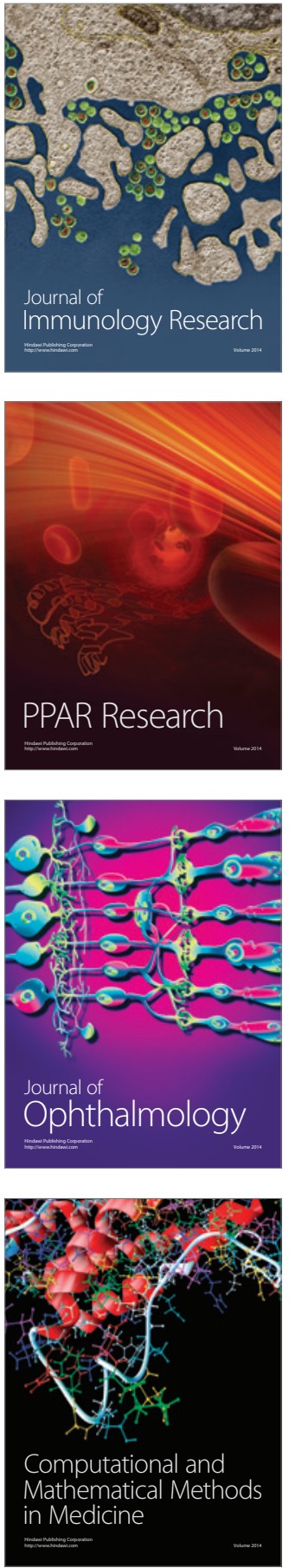

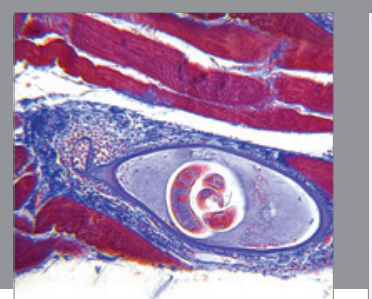

Gastroenterology Research and Practice

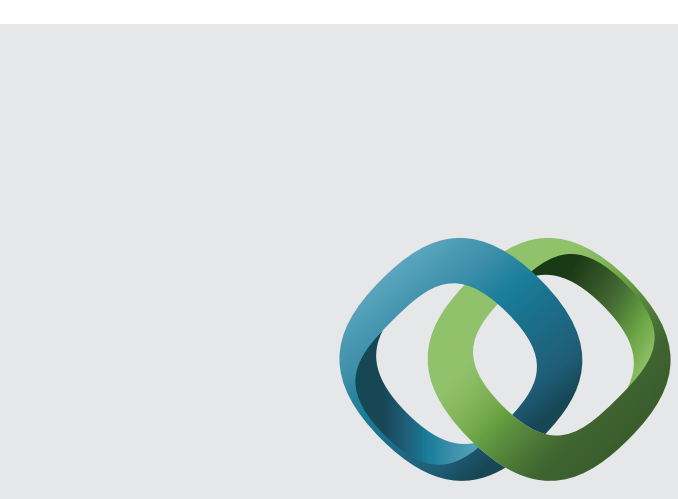

\section{Hindawi}

Submit your manuscripts at

http://www.hindawi.com
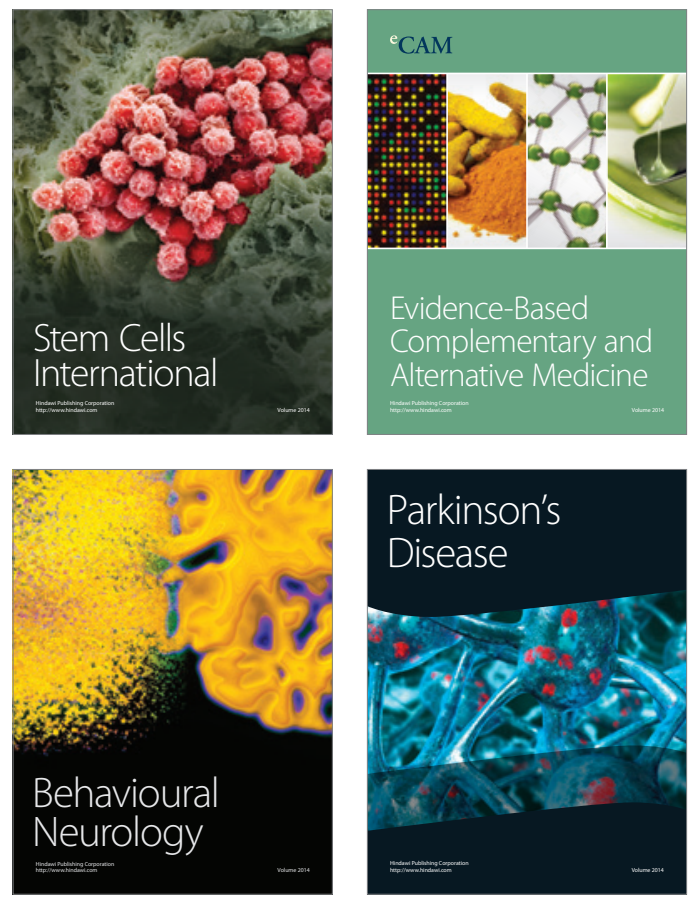
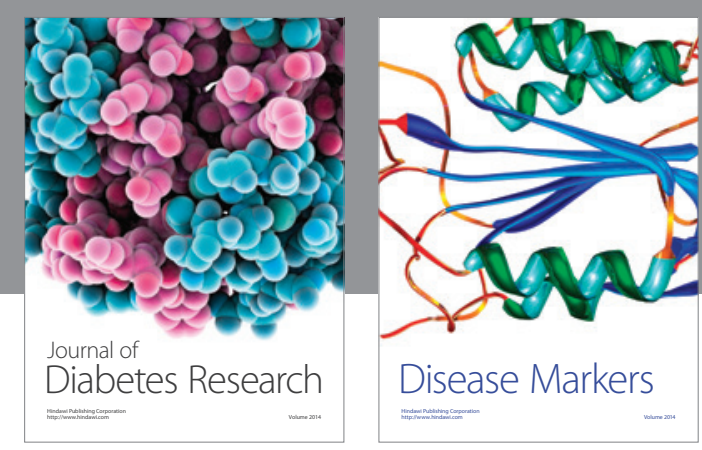

Disease Markers
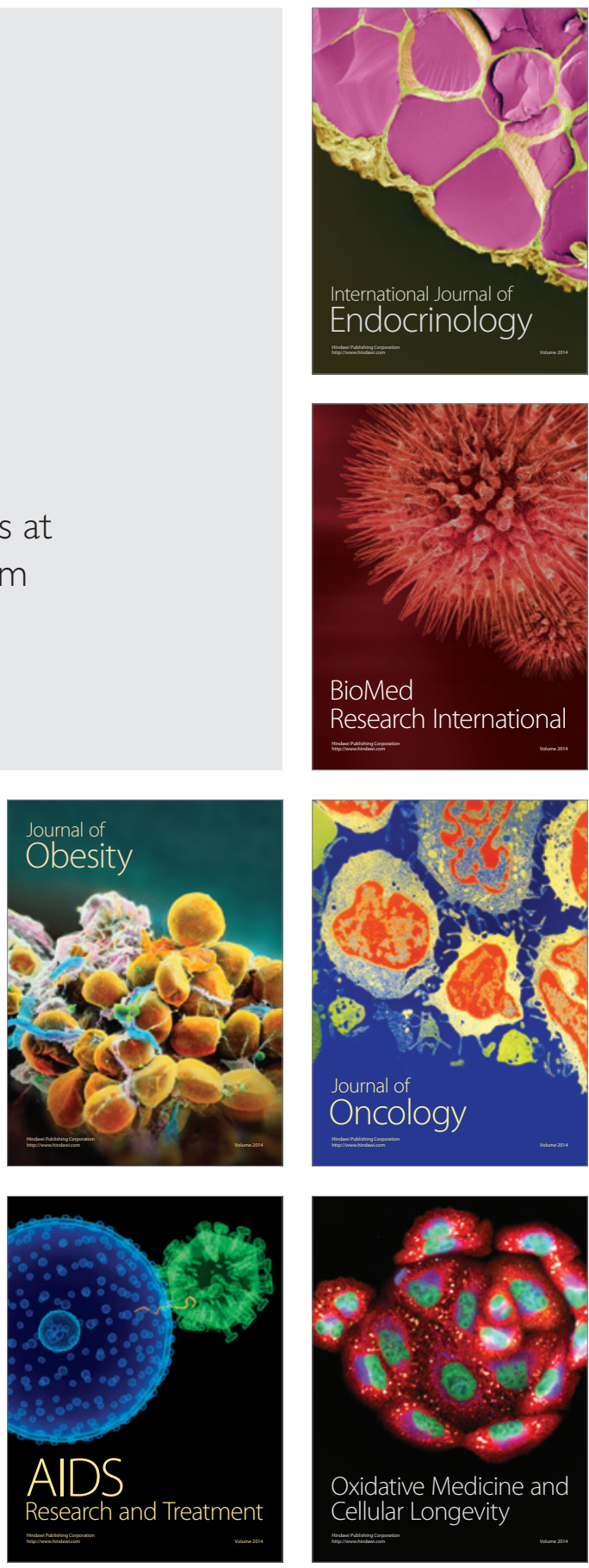